\title{
Estudo comparativo entre avaliações esqueléticas e do perfil tegumentar utilizadas no diagnóstico ortodôntico sagital
}

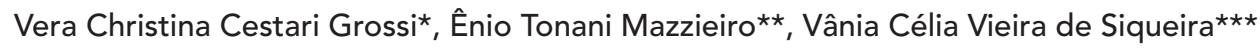

\begin{abstract}
Resumo
Objetivo: este trabalho objetivou comparar o diagnóstico de grandezas cefalométricas angulares e lineares rotineiramente utilizadas na determinação da posição sagital das bases ósseas, comparando-as com o diagnóstico de medidas lineares de tecido tegumentar, verificando a possibilidade ou não de concordância entre elas. Metodologia: analisou-se 30 telerradiografias, obtidas em norma lateral e em posição natural da cabeça (PNC), de jovens do gênero feminino, entre 20 e 26 anos de idade (média de 21,3 anos). Comparou-se os diagnósticos das medidas cefalométricas sagitais (SNA, SNB, profundidade facial, profundidade maxilar, Nperp-A e Nperp-P) entre si e com os das medidas sagitais tegumentares (Snvert-Ls, SnvertLi e Snvert-Pog'). Resultados e Conclusão: os resultados permitiram concluir que ocorreu uma fraca concordância entre os diagnósticos sugeridos pelas medidas esqueléticas e tegumentares, bem como aquele sugerido pelas diferentes medidas esqueléticas, quando comparados entre si.
\end{abstract}

Palavras-chave: Cefalometria. Diagnóstico ortodôntico. Análise facial.

Posição natural da cabeça (PNC).

\section{INTRODUÇÃO}

A complexidade do diagnóstico ortodôntico envolve a avaliação craniofacial em diversos aspectos. Durante a evolução da Ortodontia, são observadas tentativas iniciais de se avaliar as más oclusões utilizando-se modelos de gesso dos arcos dentários, posteriormente associados a modelos das faces, avaliações clínicas e, finalmente, com o advento das telerradiografias, com o auxílio das análises cefalométricas. Estas se desenvolveram com o objetivo de se tornarem elementos cada vez mais precisos e confiáveis para o diagnóstico das más oclusões e planejamento adequado de suas correções.

Por longos períodos, observou-se uma supervalorização dos dados cefalométricos, sobretudo no aspecto sagital, com a utilização de diversas medidas dentárias e esqueléticas como determinantes de

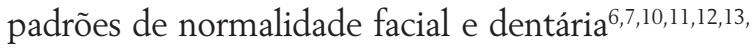
$16,25,27,32,33$.

Nessas análises, as determinações das posições sagitais da maxila e da mandíbula eram, e ainda são, consideradas os mais importantes fatores para

* Especialista em Ortodontia pela FUNBEO- USP. Mestre em Ortodontia pelo COP-PUC Minas.

** Professor Adjunto III da Disciplina de Ortodontia da PUC Minas. Doutor em Ortodontia pela USP-Bauru. Coordenador do Mestrado em Ortodontia do COP-PUC Minas.

*** Professora Assistente Doutora da Disciplina de Ortodontia do Departamento de Odontologia Infantil da Faculdade de Odontologia de Piracicaba - UNICAMP. Professora Adjunto III da Disciplina de Ortodontia da PUC Minas. 
o diagnóstico ortodôntico e ponto-chave de decisões terapêuticas. Os ortodontistas buscavam, então, uma perfeição cefalométrica em seus tratamentos, muito embora alguns resultados desastrosos pudessem ocorrer, em relação à estética facial do paciente ${ }^{1,24}$.

Dessa forma, os profissionais mais sensíveis, críticos e preocupados com as alterações dos perfis de seus pacientes começaram a procurar um meio auxiliar e alternativo de diagnóstico ortodôntico, que fornecesse informações sobre as necessidades estéticas faciais, não negligenciando os aspectos funcionais a serem alcançados em seus tratamentos.

Paralelamente, o desenvolvimento da cirurgia ortognática trouxe também a possibilidade de intervenções drásticas nas estruturas faciais, determinando a necessidade de ferramentas de diagnóstico das características de harmonia, equilíbrio e proporções faciais ${ }^{34}$. Surgiram, então, as análises e medidas tegumentares, como as de Ricketts ${ }^{26}$; Burstone ${ }^{5,6,7}$; Merrifield ${ }^{18}$; Spradley, Jacobs, Crowe ${ }^{31}$; Bass ${ }^{3}$; Arnett e Bergman ${ }^{1,2}$.

Frente a esse quadro, o diagnóstico ortodôntico encontra-se diante de contradições. Várias avaliações dentoesqueléticas não correspondem aos aspectos clínicos e tegumentares avaliados ${ }^{9,19,35}$. A ambigüidade de resultados estabelece padrões diferentes de intervenção terapêutica.

$\mathrm{Na}$ literatura, observam-se críticas em relação à determinação de diversos pontos cefalométricos empregados na determinação de planos de referência intra-cranianos, em decorrência da dificuldade de visualização e localização, além da extrema variação biológica individual encontrada ${ }^{14,23}$. Pequenas correções de planos cefalométricos são sugeridas na literatura, intencionando-se aproximar os resultados dentoesqueléticos aos faciais ou à realidade clínica do paciente ${ }^{4,15,20}$. Alguns autores sugeriram a utilização de um plano de referência extra-craniano que traduzisse a posição natural da cabeça, cuja reprodutibilidade foi testada ${ }^{8,21,28-30}$.
$\mathrm{Na}$ busca de um diagnóstico facial adequado, Spradley, Jacobs e Crowe ${ }^{31}$, em 1981, propuseram uma análise cefalométrica, baseada exclusivamente em pontos tegumentares, para determinar a posição ântero-posterior das bases ósseas. Com o paciente em posição natural de cabeça, traçaram uma linha paralela à linha vertical verdadeira, passando pelo ponto subnasal e, em relação a ela, mediram as distâncias dos pontos Lábio superior (Ls), Lábio inferior (Li) e Pogônio tegumentar (Pog'), estabelecendo padrões de normalidade para essas variáveis.

Diante desse novo aspecto, surgem algumas dúvidas: existiriam avaliações diagnósticas sagitais da posição espacial da maxila e da mandíbula, rotineiramente utilizadas e obtidas por meio do estudo cefalométrico de tecidos esqueléticos, concordantes com aquelas obtidas dos tecidos tegumentares? Existiria concordância entre os diagnósticos das várias medidas cefalométricas esqueléticas?

Dessa forma, esse trabalho propôs avaliar as possíveis semelhanças entre os diagnósticos fornecidos pelas análises cefalométricas esqueléticas sagitais e com aqueles obtidos pela utilização de uma análise baseada exclusivamente em tecido tegumentar, sugerida por Spradley, Jacobs e Crowe ${ }^{31}$.

\section{MATERIAL E MÉTODOS}

A amostra constitui-se de 30 telerradiografias obtidas em norma lateral e em posição natural de cabeça (PNC), de trinta jovens do gênero feminino, leucodermas, com idades entre 20 e 26 anos, selecionados entre os discentes do curso de Odontologia, em nível de graduação, da Faculdade de Odontologia de Piracicaba-UNICAMP. Determinou-se a posição natural da cabeça segundo o método proposto por Moorrees e Kean ${ }^{21}$, executado como descrito por Negreiros e Siqueira ${ }^{22}$ As imagens radiográficas apresentavam nitidez e contraste suficientes para uma boa visualização e identificação das estruturas ósseas, tegumentares 
e dentárias de interesse, além de ausência de distorções e trespasses horizontal e vertical avaliados, radiograficamente, entre 3 e $5 \mathrm{~mm}$.

As telerradiografias pertenciam a indivíduos que, independentemente de tratamento ortodôntico prévio, apresentavam harmonia e equilíbrio facial, com selamento labial passivo, oclusão normal segundo os preceitos de Andrews ou má oclusão de Classe I com apinhamento suave, no máximo de $2 \mathrm{~mm}$, além de todos os elementos dentários presentes e hígidos, com exceção dos terceiros molares.

Para a realização do trabalho, todos os pacientes envolvidos assinaram um Termo de Livre Consentimento e o projeto de pesquisa foi submetido à avaliação prévia da Comissão de Ética em Pesquisa, obtendo a sua aprovação.

Um mesmo técnico em Radiologia realizou todas as telerradiografias, em um único aparelho de raios X, da marca Rotograph, modelo Plus, classe I, tipo B, 85kV, 10mA, fabricado por Villa Sistemi Medicali, Itália, regularmente sob manutenção. Os filmes utilizados, da marca Kodak, de mesmo lote de fabricação e de mesma validade, sofreram exposição de $1,05 \mathrm{~s}$, numa potência de $80 \mathrm{kVp}$,

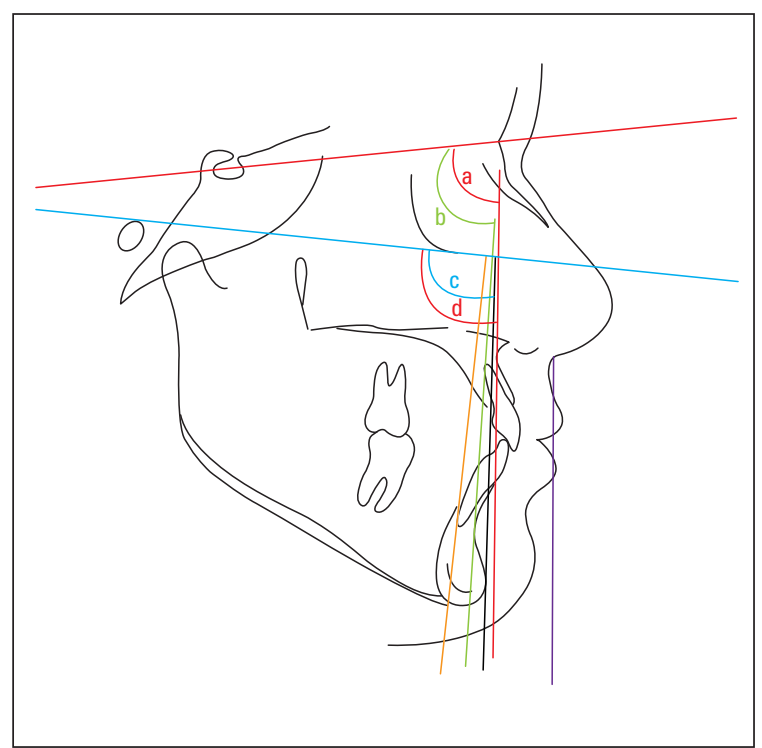

FIGURA 1 - Grandezas cefalométricas angulares: a) SNA, b) SNB, c) Profundiade facial, d) Profundidade maxilar. e foram processados pelo método temperatura/ tempo, conforme especificação do fabricante, imediatamente após a sensibilização.

Após a obtenção das radiografias, determinouse os cefalogramas utilizando-se papel Ultraphan, em sala obscurecida, delimitando-se as estruturas dentárias e esqueléticas que permitiram traçar as linhas e planos das análises cefalométricas esqueléticas sagitais de Riedel ${ }^{27}$, Ricketts ${ }^{25}$ e McNamara Jr. ${ }^{16}$ além da análise tegumentar proposta por Spradley, Jacobs e Crowe ${ }^{31}$.

As seguintes medidas cefalométricas angulares e lineares foram avaliadas: SNA, SNB, profundidade facial, profundidade maxilar, Nperp-A, NperpPog, Snvert-Ls, Snvert-Li e Snvert-Pog' (Fig. 1, 2).

No intuito de aumentar a confiabilidade e o grau de exatidão dos valores cefalométricos obtidos, cada radiografia foi traçada em dois tempos distintos, em um intervalo médio de 30 dias, por um mesmo pesquisador e conferida por outro profissional experiente. Os valores médios encontrados nas avaliações sagitais da maxila e mandíbula foram submetidos à interpretação diagnóstica, segundo cada análise cefalométrica, e classificados

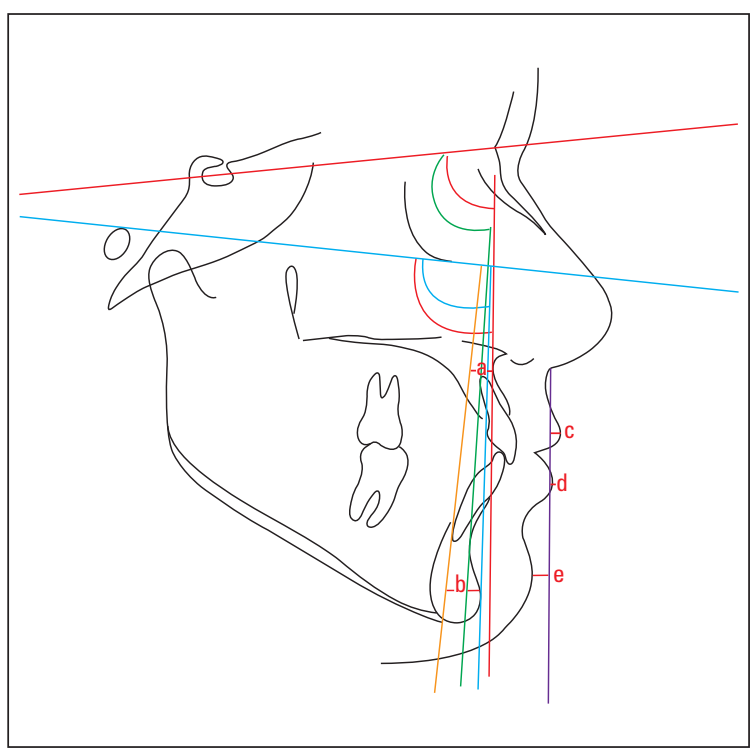

FIGURA 2 - Mensuração das grandezas lineares: a) Nperp-A, b) Nperp-Pog, c) Sn vertical-Ls, d) Sn vertical- Li, e) Sn vertical- Pog'. 
de acordo com suas posições em: protruída, bem posicionada e retruída. As interpretações diagnósticas foram, então, submetidas aos testes estatísticos, avaliando-se as hipóteses:

H0: não ocorrem diferenças entre os diagnósticos sagitais das análises cefalométricas.

$\mathrm{Hl}$ : ocorrem diferenças significativas entre os diagnósticos sagitais das análises cefalométricas.

Com o propósito de se comparar as informações diagnósticas obtidas das medidas esqueléticas com aquelas das avaliações tegumentares, foram aplicados os testes estatísticos, de forma a se verificar a sensibilidade $(\mathrm{S})$, a especificidade (E), o valor preditivo positivo (VPP), o valor preditivo negativo (VPN), o falso positivo (FP) e o falso negativo (FN). Os diagnósticos estabelecidos pelas variáveis Snvert-Ls, Snvert-Li e Snvert-Pog' foram considerados como padrão-ouro para a análise estatística dos dados.

Utilizou-se o índice de concordância Kappa, um teste não paramétrico, para avaliar o nível de concordância entre os diagnósticos das análises, avaliadas duas a duas e interpretadas segundo a tabela 1 . Todos os resultados foram considerados significativos para uma probabilidade de significância inferior a 5\% $(\mathrm{p}<0,05)$.

\section{RESULTADOS}

Verificou-se a acuidade dos diagnósticos das medidas cefalométricas esqueléticas, determinantes da posição ântero-posterior da maxila e da mandíbula, na predição de medidas alteradas, tomando-se como padrão-ouro o diagnóstico das medidas tegumentares. Testou-se a sensibilidade (S), a especificidade (E), o valor preditivo positivo (VPP), o valor preditivo negativo (VPN), o falso

Tabela 1 - Interpretação do índice Kappa.

\begin{tabular}{cc}
\hline intervalo & interpretação \\
\hline$<0,40$ & concordância fraca \\
0,40 a 0,75 & concordânca de razoável a boa \\
$\geq 0,75$ & concordância excelente \\
\hline
\end{tabular}

positivo (FP) e o falso negativo (FN) dos diagnósticos esqueléticos. Os resultados são apresentados na tabela 2.

A sensibilidade mede a capacidade de um exame identificar medidas com alterações nas características de normalidade, enquanto a especificidade mede a capacidade de um exame identificar as medidas normais. Idealmente, os parâmetros de diagnóstico deveriam ser 100\% sensíveis e específicos. Observando-se a tabela 2, nota-se que nenhuma variável apresentou sensibilidade e especificidade diagnóstica suficiente para ser utilizada isoladamente.

O valor preditivo positivo avalia a probabilidade da variável identificar corretamente uma medida alterada. Idealmente, esse valor deveria ser de $100 \%$. Nos casos em que isso não acontece, estabelecem-se os falsos positivos, que representam a probabilidade da variável identificar erroneamente uma medida alterada. Na tabela 2, observa-se que os valores preditivos positivos oscilaram entre $44,4 \%$ e $75 \%$, indicando a possibilidade de erros diagnósticos entre as variáveis analisadas.

O valor preditivo negativo avalia a probabilidade do parâmetro identificar corretamente uma medida normal. Idealmente, esse valor deveria ser de $100 \%$. Nos casos em que isso não acontece, estabelecem-se os falsos negativos, que representam a probabilidade da variável identificar incorretamente uma medida normal. Novamente, a tabela 2 apresenta variações para o valor preditivo negativo entre $14,3 \%$ e $33,3 \%$.

A avaliação das concordâncias entre os diagnósticos fornecidos pelas análises tegumentares e esqueléticas foi realizada pelo índice de concordância de Kappa, que mostrou baixas concordâncias.

Avaliou-se também, por meio do índice Kappa, a concordância das análises esqueléticas entre si. Os resultados na tabela 3 mostram, novamente, baixas concordâncias entre as variáveis esqueléticas utilizadas para diagnosticar as posições sagitais de maxila e mandíbula. 
Tabela 2 - Resultados das análises estatísticas.

\begin{tabular}{|c|c|c|c|c|c|c|c|c|}
\hline & $\begin{array}{l}\text { sensibili- } \\
\text { dade }\end{array}$ & $\begin{array}{l}\text { especifi- } \\
\text { cidade }\end{array}$ & $\begin{array}{l}\text { valor predi- } \\
\text { tivo positivo }\end{array}$ & $\begin{array}{c}\text { falso } \\
\text { positivo }\end{array}$ & $\begin{array}{l}\text { valor predi- } \\
\text { tivo negativo }\end{array}$ & $\begin{array}{c}\text { falso } \\
\text { negativo }\end{array}$ & $\begin{array}{l}\text { índice } \\
\text { Kappa }\end{array}$ & valor $\mathbf{P}$ \\
\hline SNA X Snvert-Ls & $45 \%$ & $40 \%$ & $60 \%$ & $40 \%$ & $26,7 \%$ & $73,3 \%$ & 0,0 & 1 \\
\hline Nperp-A X Snvert-Ls & $75 \%$ & $20 \%$ & $65,2 \%$ & $34,8 \%$ & $28,6 \%$ & $71,4 \%$ & 0,0 & 1 \\
\hline $\begin{array}{c}\text { profundidade maxilar X } \\
\text { Snvert-Ls }\end{array}$ & $25 \%$ & $50 \%$ & $50 \%$ & $50 \%$ & $25 \%$ & $75 \%$ & 0,0 & 1 \\
\hline SNB X Snvert- Pog' & $60 \%$ & $60 \%$ & $75 \%$ & $25 \%$ & $42,9 \%$ & $57,1 \%$ & 0,182 & 0,30 \\
\hline Nperp- Pog X Snvert- Pog' & $70 \%$ & $10 \%$ & $60,9 \%$ & $39,1 \%$ & $14,3 \%$ & $85,7 \%$ & 0,0 & 1 \\
\hline $\begin{array}{l}\text { profundidade facial X } \\
\text { Snvert-Pog' }\end{array}$ & $25 \%$ & $60 \%$ & $55,6 \%$ & $44,4 \%$ & $28,6 \%$ & $71,4 \%$ & 0,0 & 1 \\
\hline SNB X Snvert- Li & $55,6 \%$ & $50 \%$ & $62,5 \%$ & $37,5 \%$ & $42,9 \%$ & $57,1 \%$ & 0,054 & 0,765 \\
\hline N-perp Pog X Snvert- Li & $77,8 \%$ & $25 \%$ & $60,9 \%$ & $39,1 \%$ & $42,9 \%$ & $57,1 \%$ & 0,030 & 0,860 \\
\hline $\begin{array}{c}\text { profundidade facial X } \\
\text { Snvert-Li }\end{array}$ & $22,2 \%$ & $58,3 \%$ & $44,4 \%$ & $55,6 \%$ & $33,3 \%$ & $66,7 \%$ & 0,0 & 1 \\
\hline
\end{tabular}

Tabela 3 - Correlação entre as medidas cefalométricas esqueléticas sagitais entre si.

\begin{tabular}{cc}
\hline & índice Kappa \\
\hline SNA x Nperp-A & 0,333 \\
SNA x profundidade maxilar & 0,400 \\
Nperp-A x profundidade maxilar & 0,264 \\
SNB x Nperp-Pog & 0,240 \\
SNB x profundidade facial & 0,286 \\
Nperp-Pog x profundidade facial & 0,231 \\
\hline
\end{tabular}

\section{DISCUSSÃO}

O presente trabalho intencionou verificar as possiveis concordâncias existentes entre os diagnósticos cefalométricos sagitais definidos pelas análises esqueléticas, em relação aos padrões estabelecidos pela avaliação objetiva da face, determinada pela análise facial de Spradley, Jacobs e Crowe $^{31}$. Buscou-se apurar quais as análises traduziriam melhor a realidade facial do paciente, no intuito de direcionar e fundamentar a seleção dos critérios empregados no diagnóstico e planificação ortodônticos.

Escolheu-se a análise de Spradley, Jacobs e Crowe $^{31}$ para a avaliação ântero-posterior da posição de maxila e mandíbula, por ser considerada de aplicação simples e fácil execução. A principal vantagem dessa análise é a utilização do ponto subnasal para traçar linhas perpendiculares que permitem a mensuração cefalométrica da posição dos lábios, estabelecendo-se os padrões de diagnóstico.

Dessa forma, os diagnósticos determinados por essa análise facial foram estabelecidos como padrão-ouro, ao qual compararam-se as outras interpretações diagnósticas obtidas nas análises cefalométricas sagitais esqueléticas. As concordâncias entre essas avaliações, uma vez encontradas, poderiam estabelecer um critério de diagnóstico que favorecesse os aspectos faciais, dentários e esqueléticos, sem contradições entre os resultados.

Para essas avaliações, as medidas cefalométricas sagitais esqueléticas SNA, SNB, profundidade facial, profundidade maxilar, Nperp-A e Nperp-Pog foram escolhidas, por representarem análises mais rotineiramente utilizadas no diagnóstico e citadas pela literatura.

Utilizou-se a posição natural da cabeça para as tomadas das telerradiografias, pois esta representa um importante fator para o diagnóstico. Como a literatura demonstra, a determinação da posição horizontal natural da cabeça foi buscada por meio da determinação de linhas e planos intracranianos que permitissem a reprodutibilidade dessa posição e a orientação dos estudos ${ }^{4,13,15}$. Entretanto, demonstrou-se a grande variação dos planos de 
referência intracranianos, sobretudo considerando a dificuldade de identificação dos pontos cefalométricos nas telerradiografias, bem como a grande variação biólogica na posição das estruturas ${ }^{14,23}$. Segundo Moorrees e Kean ${ }^{21}$, uma vez que a inclinação e a angulação das linhas de referência intracranianas exibem grandes variações individuais, elas são inadequadas para orientar as análises cefalométricas importantes, pois permitem uma gama de interpretações errôneas. Assim sendo, o registro da cabeça em sua posição natural, com o paciente olhando para a imagem de seus olhos refletidos em um espelho, seria uma excelente linha de referência extracraniana, tendo sido recomendado, para utilização em telerradiografias, por diversos autores ${ }^{4,14,15,20,21,22,29,30}$.

Avaliou-se, inicialmente, a concordância entre o diagnóstico sugerido pelas diferentes medidas cefalométricas dentoesqueléticas com as tegumentares, para testar se uma ou mais delas são eficazes em retratar a realidade facial do paciente. Em seguida, compararam-se as medidas dentoesqueléticas entre si, para testar a credibilidade de suas interpretações e sua validade como ferramenta de diagnóstico. Se todas as medidas propostas visam determinar a posição ântero-posterior das bases ósseas, seus resultados deveriam apresentar alguma concordância.

Avaliando a posição sagital da maxila, sugerida pela medida esquelética SNA de Riedel ${ }^{27} \mathrm{em}$ relação àquela sugerida pela medida Snvert-Ls de Spradley, Jacobs e Crowe ${ }^{31}$, verifica-se uma fraca concordância, uma vez o índice Kappa foi igual a 0 . Conforme demonstrado na tabela 2 , o valor de sensibilidade de $45 \%$ encontrado denota uma deficiência da análise esquelética em identificar corretamente as alterações na posição sagital da maxila, quando comparada ao padrãoouro utilizado. O valor da especificidade encontrado demonstra que, em apenas $40 \%$ das vezes, a medida SNA é capaz de identificar a posição normal da maxila, comparada ao diagnóstico da análise de tecido mole. Esses resultados estão de acordo com as citações de Burstone ${ }^{7}$, que comprovou a extrema variabilidade do tecido tegumentar em espessura, tonicidade e comprimento, mostrando que, muitas vezes, o diagnóstico dentoesquelético não traduz a verdadeira desarmonia facial, que pode estar mascarada pelas características tegumentares. Os resultados também estão de acordo com os de Michiels e Tourne $^{19}$, que apontaram a total independência entre a posição sagital da maxila, determinada pela análise esquelética, e a posição definida pela análise do perfil tegumentar.

Outra explicação para tamanha discrepância pode ser a grande variação da linha sela-násio em relação ao plano horizontal verdadeiro, obtido com a cabeça em posição natural, como descreveram Moorrees, Kean ${ }^{21}$ e Mills ${ }^{20}$. Talvez a correção de $5^{\circ}$ da linha sela-násio, para cima ou para baixo, em relação à horizontal verdadeira possa tornar o resultado mais fiel à realidade clínica e tegumentar, conforme proposta de Mills ${ }^{20}$. É conveniente registrar que Ozbeck e Köklu ${ }^{23}$ comprovaram que a variação da inclinação da linha sela-násio resulta em alteração da posição ântero-posterior dos pontos A, B e Pog, originando falsa interpretação do prognatismo facial.

A tabela 3 apresenta a concordância entre a medida Nperp-A, proposta por McNamara Jr. ${ }^{16}$, e a medida Snvert-Ls, tomada como padrão-ouro. $\mathrm{O}$ índice Kappa igual a 0 (Tab. 2) revela também fraca concordância entre os diagnósticos sugerido pelos dois métodos. $\mathrm{O}$ valor de sensibilidade demonstra que, em $75 \%$ das vezes, a medida Nperp-A identificou corretamente a posição alterada da maxila, concordando com Snvert-Ls. Por outro lado, com especificidade de $20 \%$, nota-se que, em pequeno número de casos, a medida esquelética identificou a posição normal da maxila em concordância com a análise tegumentar. Dessa forma, essa medida não apresentaria validade clínica, quando do diagnóstico da posição da maxila exatamente como ela se apresenta na face. Convém mencionar aqui a afirmação de McNamara Jr. e Brudon ${ }^{17}$, de que a 
posição ântero-posterior da maxila não poder ser definida por essa medida cefalométrica isolada, mas deve associar-se à avaliação do ângulo nasolabial. Nos casos onde existe a divergência entre a interpretação cefalométrica e a observação clínica do ângulo nasolabial, estes autores sugerem que o exame clínico seja soberano, evitando-se tratar o paciente em função de normas cefalométricas rígidas. Esses resultados também concordam com aqueles de Michiels e Tourne ${ }^{19}$, denotando total independência entre os diagnósticos. A justificativa para tal divergência pode também residir na variação biológica verificada nos pontos que determinam o plano de Frankfürt, bem como sua dificuldade de identificação ${ }^{14,21}$. A possibilidade do plano de Frankfürt apresentar menor variação em relação à horizontal verdadeira do que a linha sela-násio justificaria o melhor comportamento dessa medida em identificar a posição alterada da maxila, quando comparada ao SNA. Mas ainda assim é ineficiente em retratar a realidade clínica ditada pela análise tegumentar.

Avaliando a concordância entre a medida profundidade maxilar de Ricketts ${ }^{25}$ e a medida Snvert-LS, na tabela 2, verifica-se o índice Kappa de 0 , significando também fraca concordância. O valor de sensibilidade de $25 \%$ representa uma baixa eficiência da medida esquelética no julgamento correto da posição alterada da maxila, em comparação à medida tegumentar. $\mathrm{O}$ valor de especificidade de $50 \%$ denota que apenas na metade dos casos a medida profundidade facial identificou como normal a posição sagital da maxila, concordando com a medida Snvert-Ls. O comportamento é semelhante às duas medidas testadas inicialmente e as justificativas se aplicam da mesma forma, uma vez que a profundidade maxilar também utiliza o plano de Frankfürt como linha de referência.

Avaliando a concordância da medida SNB de Riedel $^{27}$ com a medida Snvert-Pog' verifica-se, conforme a tabela 2, um indice Kappa de 0,182 $(\mathrm{p}=0,3006)$, demonstrando, ainda, fraca concor- dância, porém maior que as apresentadas anteriormente. Encontraram-se valores iguais para a sensibilidade e a especificidade, correspondendo a $60 \%$, o que revela que, em $60 \%$ dos casos, as medidas utilizadas concordam na identificação tanto da posição sagital alterada quanto da posição normal.

Esses resultados mostraram que o SNB comporta-se de melhor maneira que o SNA na determinação da posição sagital da base óssea, o que está de acordo com as conclusões de Michiels e Tourne $^{19}$. O índice Kappa apresentado mostrouse o maior dentre todas as avaliações, retratando que o SNB é a medida esquelética que melhor se relaciona à medida tegumentar. Mas esses resultados ainda caracterizam o SNB como pouco eficiente em representar a posição mandibular, ao contrário do afirmado no trabalho citado anteriormente. A justificativa residiria na ampla gama de variações a que se submete a linha selanásio ${ }^{13,14}$.

A concordância entre a medida Nperp-Pog de McNamara Jr. ${ }^{16}$ e Snvert-Pog' é demonstrada na tabela 2. O índice Kappa igual a 0 demonstra fraca concordância. $\mathrm{O}$ valor de sensibilidade obtido aponta que em 70\% dos casos ocorreu concordância em identificar a posição alterada da mandíbula. Essa medida é a que mais se ajusta à análise tegumentar, quanto à identificação da alteração, mas por outro lado, em apenas $10 \%$ dos casos, verificou-se concordância ao identificar a posição normal. A análise de McNamara $\mathrm{Jr}^{16}$. mais uma vez apresenta dificuldades para retratar a condição clínica do paciente, quanto à posição ântero-posterior da mandíbula, em função da variação do plano de Frankfürt, aproximando-se estes resultados daqueles do trabalho de Michiels e Tourne ${ }^{19}$, que relata a extrema variabilidade e a difícil identificação do pório anatômico na correta determinação desse plano de referência.

A tabela 3 demonstra a concordância entre a medida profundidade facial de Ricketts ${ }^{25}$ e Snvert-Pog', com um índice Kappa de $0(\mathrm{p}=1,0)$ 
apontando também fraca concordância. Encontrou-se um valor de sensibilidade de $25 \%$, representando baixa concordância ao identificar a posição alterada, em comparação com a medida tegumentar. Por outro lado, em $60 \%$ dos casos, tais medidas se equivaleram, ao identificar a posição sagital normal. Os resultados, novamente, confirmam aqueles de Michiels e Tourne ${ }^{19}$. A variação do plano de Frankfürt como linha de referência pode ser também aqui invocada como justificativa dessa discrepância, conforme Moorrees, Kean $^{21}$; Lundström e Lundström ${ }^{14}$.

Avaliando a medida SNB de Riedel ${ }^{27}$ em relação a Snvert-Li, na tabela 2, encontra-se uma fraca concordância demonstrada por um índice Kappa de 0,054 ( $p=0,7651)$. Verificando o valor de sensibilidade, nota-se que existe concordância em 55,6\% dos casos, no que diz respeito à correta identificação da posição alterada. Em contrapartida, uma especificidade de 50\% representa que em apenas metade dos casos há concordância quanto ao diagnóstico da posição sagital normal.

A relação entre a medida Nperp-Pog de McNamara Jr. ${ }^{16}$ e Snvert-Li de Spradley, Jacobs e Crowe ${ }^{31}$, apresentou um índice Kappa de 0,030 $(\mathrm{p}=0,8601)$, revelando, uma vez mais, fraca concordância. A sensibilidade de $77,8 \%$ aponta que a medida esquelética é razoavelmente eficiente em identificar as medidas alteradas, concordando um número maior de casos. Entretanto, é pouco eficiente em detectar a posição normal, concordando em apenas $25 \%$ dos casos, conforme ditado pelo valor de especificidade.

A fraca concordância entre as medidas profundidade facial de Ricketts ${ }^{25}$ e a Snvert-Li foi mostrada através do índice Kappa de $0(p=1,0)$. Valores de sensibilidade e especificidade, respectivamente, de $22,2 \%$ e $58,3 \%$ demonstram que essa medida esquelética não concorda com a medida tegumentar na identificação nem da posição equilibrada, nem da posição alterada.

Em síntese, pode-se afirmar que, dentre as medidas esqueléticas utilizadas, a medida SNB de Riedel $^{27}$ foi a que apresentou melhor concordância com a análise tegumentar para diagnóstico sagital da mandíbula, apesar de ainda classificar-se como fraca em relação à SnvertPog' (Kappa=0,182) e em relação à Snvert-Li (Kappa=0,054). Em segundo lugar apresenta-se a medida Nperp-Pog de McNamara Jr. ${ }^{16}$, com índice Kappa de 0,030.

As comparações entre os diagnósticos apresentados pelas análises esqueléticas entre si mostraram maiores concordâncias, porém pelo índice Kappa pode-se classificá-las como fracas. As medidas que mais concordaram entre si, apresentando maior índice, foram SNA e profundidade maxilar.

Esses dados corroboram as afirmações de Mills $^{20}$ que, ao encontrar tantas controvérsias entre as análises cefalométricas, propôs um método de correção das linhas e planos de referência intracranianos e a utilização do diagrama milimetrado, capacitando o ortodontista a planejar o tratamento de seu paciente de forma mais adequada às suas reais necessidades.

Os dados coincidem também com os de Wylie, Fish e Epker ${ }^{35}$ que, apesar de utilizarem metodologias diferentes e compararem outras análises cefalométricas, encontraram baixa concordância entre elas. A comparação incluia análises esqueléticas e tegumentares, e os resultados também revelaram que as análises cefalométricas, por si só, não podem ser consideradas ferramentas principais de diagnóstico das deformidades dentofaciais.

Essas fracas concordâncias colocam em cheque a utilização das análises cefalométricas como ferramenta única de diagnóstico e planificação do tratamento ortodôntico. Só existe um diagnóstico da posição ântero-posterior das bases ósseas de cada paciente e o método capaz de identificála ainda precisa ser melhor determinado. As avaliações cefalométricas dos pacientes devem ser analisadas segundo uma visão crítica, não sendo subestimados os aspectos da harmonia facial do 
paciente e a sensibilidade clínica do ortodontista. Esses dois últimos fatores se mostram mais importantes na determinação dos objetivos dos tratamentos que aqueles estabelecidos por padrões rígidos cefalométricos.

\section{CONCLUSÕES}

Segundo os resultados apresentados, conclui-se que não ocorreram concordâncias entre os diag- nósticos sugeridos pelas diferentes análises cefalométricas, tanto nas comparações daquelas baseadas em tecido esquelético entre si, quanto nas comparações entre as esqueléticas com a de tecido tegumentar, utilizada como padrão-ouro.

\title{
Comparative study between skeletal and tegumental measurements used in sag- ital orthodontic diagnosis
}

\begin{abstract}
Aim: This study aimed to evaluate skeletal measures used in sagital diagnosis of both jaws in comparison with tegumental measures, verifying the agreement between themselves. Methods: Cephalometric radiographs in natural head position were obtained from 30 white females, between 20 and 26 years of age, mean 21,3 years. Cephalometric tracings were taken and the following measurements recorded: SNA, SNB, Facial depth, Maxillary depth, Nperp-A, Nperp-Pog, and then compared to the tegumental measurements Snvert-Ls, Snvert-Li Snvert-Pog'. Results and Conclusions: The results showed low agreement between the diagnosis proposed by different hard tissue and soft tissue analysis, as well as the different hard tissue measures when compared to themselves.
\end{abstract}

Key words: Orthodontics. Cephalometrics. Orthodontic diagnosis. Facial analysis. Natural Head Position.

\section{REFERÊNCIAS}

1. ARNETT, W.; BERGMAN, R. Facial keys to orthodontic diagnosis and treatment planning. Part I. Am. J. Orthod. Dentofacial Orthop., St. Louis, v. 103, no. 4, p. 299-312, Apr. 1993.

2. ARNETT, W.; BERGMAN, R. Facial keys to orthodontic diagnosis and treatment planning. Part II. Am. J. Orthod. Dentofacial Orthop., St. Louis, v. 103, no. 5, p. 395-411, Apr. 1993.

3. BASS, N. M. The aesthetic analysis of the face. Eur. J. Orthod., Oxford, v. 13, p. 343-350, 1991.

4. BJERIN, R. A comparison between the Frankfort horizontal and the sella turcica-nasion as reference planes in cephalometric analysis. Acta Odontol. Scand., Oslo, v. 15, no. 4, p. 1-12, 1957.

5. BURSTONE, C. J. The integumental profile. Am. J. Orthod., St. Louis, v. 44, no. 1, p. 1-25, Jan. 1958.

6. BURSTONE, C. J. Integumental contour and extension patterns. Angle Orthod., Appleton, v. 29, no. 2, p. 93-104, Apr. 1959.

7. BURSTONE, C. J. Lip posture and its significance in treatment planning. Am. J. Orthod., St. Louis, v. 53, no. 4, p. 263-284, Apr. 1967.

8. COOKE, M. S.; WEI, H. Y. The reproducibility of natural head posture: a methodological study. Am. J. Orthod. Dentofacial Orthop., St. Louis, v. 93, no. 4, p. 280-288, Apr. 1988.

9. DE SMIT, A.; DERMAUT L. Soft-tissue profile preference. Am. J. Orthod., St. Louis, v. 86, no. 1, p. 67-73, July 1984.

10. DOWNS, W. B. The role of cephalometrics in orthodontic case analysis and diagnosis. Am. J. Orthod., St. Louis, v. 38, no. 3, p. 162-182, Mar. 1952.

11. HELLMAN, M. Some facial features and their orthodontic implications. Am. J. Orthod., St. Louis, v. 25, no. 10, p. $927-$ 951, Oct. 1939.
12. INTERLANDI, S. Linha I na análise morfodiferencial para o diagnóstico ortodôntico. Rev. Faculd. Odontol. S. Paulo São Paulo, v. 9, n. 2, p. 289-310, jul./dez. 1971.

13. KROGMAN, W. M.; SASSOUNI, V. A. A syllabus in roentgenographic cephalometry. Philadelphia: Center for research in child growth, University of Pennsylvania, 1957.

14. LUNDSTROM, A.; LUNDSTROM, F. Natural Head Position as a basis for cephalometric analysis. Am. J. Orthod. Dentofacial Orthop., St. Louis, v. 101, no. 3, p. 244-247, Mar. 1992.

15. LÜTHY, A. Die vertikale gesichtsprofilierung und das problem des schädelhorisontalen. Arch. F. Anthropol. Neue Folge, [s.I.], v. 11, 1912.

16. MCNAMARA JR., J. A. A method for cephalometric evaluation. Am. J. Orthod., St. Louis, v. 86, no. 6, p. 449-469, Dec. 1984

17. McNAMARA JR., J. A.; BRUDON, W. Evaluación cefalométrica. In: ___. Tratamiento ortodóncico y ortopédico en la denticion mixta. Ann Arbor: Needham Press, 1995. cap. 2, p. 13-54.

18. MERRIFIELD, L. L. The profile line as an aid in critically evaluating facial esthetics. Am. J. Orthod., St. Louis, v. 52, no. 11, p. 804-822, Nov. 1966.

19. MICHIELS, L. Y. F.; TOURNE, L. P. M. Nasion true vertical: a proposed method for testing the clinical validity of cephalometric measurements applied to a new cephalometric reference line. Int. J. Adult Orthod. Orthognath. Surg., Carol Stream, v. 5, no. 1, p. 43-52, 1990.

20. MILLS, P. B. A grid and visual head positioning as adjuncts to cephalometric analysis. Am. J. Orthod., St. Louis, v. 54, no. 7, p. 521-531, July 1968. 
21. MOORREES, C. F. A.; KEAN, M. R. Natural head position, a basic consideration in the interpretation of cephalometric radiographs. Am. J. Phys. Anthropol., New York, v. 16, no. 2, p. 213-235, 1958.

22. NEGREIROS, P. E.; SIQUEIRA, V. C. V. O efeito da alteração da posição natural da cabeça (PNC) sobre as medidas cefalométricas. Rev. Dental Press Ortodon. Ortop. Maxilar, Maringá, v. 9, n. 3, p. 59-76, 2004

23. ÖZBECK, M. M.; KÖKLÜ, A. Natural cervical inclination and craniofacial structure. Am. J. Orthod. Dentofacial Orthop., St. Louis, v. 106, no. 6, p. 584-591, Dec. 1993.

24. PARK,Y. C.; BURSTONE, C. J. Soft-tissue profile - Fallacies of hard-tissue standards in treatment planning. Am. J. Orthod. Dentofacial Orthop., St. Louis, v. 90, no.1, p. 52-62, July 1986.

25. RICKETTS, M. A foundation for cephalometric communication. Am. J. Orthod., St. Louis, v. 46, no. 5, p. 330-355, May 1960.

26. RICKETTS, M. Planning treatment on the basis of the facial pattern and an estimate of its growth. Angle Orthod., v. 27, no. 1, p. 14-37, Jan. 1957.

27. RIEDEL, R. A The relation of maxillary structures to cranium in malocclusion and in normal occlusion. Angle Orthod., Appleton, v. 22 , no. 3, p. 142-145, July 1952.
28. SHOWFETY, K. J. VIG, P. S.: MATTESON, S. A simple method for taking natural-head-position cephalograms Am. J. Orthod. St. Louis, v. 83, no. 6, p. 495-500, June 1983.

29. SIERSBAEK-NIELSEN, S.; SOLOW, B. Intra- and interexaminer variability in head posture recorded by dental auxiliares. Am. J. Orthod. St. Louis, v. 82, no. 1, p. 50-57, July 1982

30. SOLOW, B.; TALLGREN, A. Dentoalveolar morphology in relation to craniofacial posture. Angle Orthod, Appleton, v. 47, no. 3, p. 157-164, July 1977.

31. SPRADLEY, F. L.; JACOBS, J. D.; CROWE, D. P. Assessment of the anterior-posterior soft tissue contour of the lower facial third of the ideal young adult. Am. J. Orthod., St. Louis, v. 79, no. 3, p. 316-325, Mar. 1981.

32. STEINER, C. C. Cephalometrics for you and me. Am. J. Orthod. St. Louis, v. 39, no. 10, p. 729-755, Oct. 1953

33. TWEED, C. H. Clinical Orthodontics. St. Louis: C. V. Mosby, 1966

34. WALLEN, T.; BLOOMQUIST, D. The clinical examination: is it more important than cephalometric analysis in surgical orthodontics? Int. J. Adult Orthod. Orthognath. Surg., Chicago, v. 1, no. 3, p. 179-191, 1986.

35. WYLIE, G. A.; FISH, L. C.; EPKER, B. N. Cephalometrics: a comparison of five analysis currently use in the diagnosis of dentofacial deformities. Int. J. Adult Orthod. Orthognath. Surg., Chicago, v. 2, no. 1, p. 15-36, 1987.
Endereço para correspondência

Enio Tonani Mazzieiro

Av. Dom José Gaspar 500, Prédio 46, Coração Eucarístico

CEP: 14.090-210 - Belo Horizonte / MG

E-mail: mazzieiro@pucminas.br 